\title{
Dependency of particle size distribution at dust emission on friction velocity and atmospheric boundary-layer stability
}

\author{
Yaping Shao $^{1}$, Jie Zhang ${ }^{2}$, Masahide Ishizuka ${ }^{3}$, Masao Mikami ${ }^{4}$, John Leys ${ }^{5,6}$, and Ning Huang ${ }^{2}$ \\ ${ }^{1}$ Institute for Geophysics and Meteorology, University of Cologne, Cologne Germany \\ ${ }^{2}$ Key Laboratory of Mechanics on Disaster and Environment in Western China, Lanzhou University, Lanzhou, China \\ ${ }^{3}$ Faculty of Engineering and Design, Kagawa University, Takamatsu, Japan \\ ${ }^{4}$ Office of Climate and Environmental Research Promotion, Japan Meteorological Business Support Center, Tokyo, Japan \\ ${ }^{5}$ Department of Planning, Industry and Environment, New South Wales, Lidcombe Australia \\ ${ }^{6}$ The Fenner School of Environment \& Society, The Australian National University, Canberra, Australia
}

Correspondence: Jie Zhang (zhang-j@1zu.edu.cn) and Ning Huang (huangn@1zu.edu.cn)

Received: 30 April 2020 - Discussion started: 18 May 2020

Revised: 25 August 2020 - Accepted: 23 September 2020 - Published: 5 November 2020

\begin{abstract}
Particle size distribution of dust at emission (dust PSD) is an essential quantity to estimate in dust studies. It has been recognized in earlier research that dust PSD is dependent on soil properties (e.g. whether soil is sand or clay) and friction velocity, $u_{*}$, which is a surrogate for surface shear stress and a descriptor for saltation-bombardment intensity. This recognition has been challenged in some recent papers, causing a debate on whether dust PSD is "invariant" and the search for its justification. In this paper, we analyse the dust PSD measured in the Japan Australian Dust Experiment and show that dust PSD is dependent on $u_{*}$ and on atmospheric boundary-layer (ABL) stability. By simple theoretical and numerical analysis, we explain the two reasons for the latter dependency, which are both related to enhanced saltation bombardment in convective turbulent flows. First, $u_{*}$ is stochastic and its probability distribution profoundly influences the magnitude of the mean saltation flux due to the non-linear relationship between saltation flux and $u_{*}$. Second, in unstable conditions, turbulence is usually stronger, which leads to higher saltation-bombardment intensity. This study confirms that dust PSD depends on $u_{*}$ and, more precisely, on the probability distribution of $u_{*}$, which in turn is dependent on ABL stability; consequently, dust PSD is also dependent on ABL. We also show that the dependency of dust PSD on $u_{*}$ and ABL stability is made complicated by soil surface conditions. In general, our analysis reinforces the basic conceptual understanding that dust PSD depends on saltation bombardment and inter-particle cohesion.
\end{abstract}

\section{Introduction}

Gillette (1981) explained that dust emission can be produced by aerodynamic lift and saltation bombardment, but under realistic wind conditions, aerodynamic-lift emission is much weaker than saltation-bombardment emission. This hypothesis was confirmed by Shao et al. (1993). It is recognized that saltation bombardment is the most important mechanism for dust emission, and the dust emission rate, $F$, is proportional to streamwise saltation flux, $Q .^{1}$

Rice et al. $(1995,1996)$ visualized the process of saltation bombardment using wind-tunnel photos: a saltation particle at impact onto the surface ejects a tiny amount of soil into the air, leaving behind a crater. Models for estimating crater size have been developed by, for example, Lu and Shao (1999). The fraction of dust that gets emitted from the ejection is difficult to estimate, because it depends on both inter-particle cohesion and bombardment intensity. Since inter-particle cohesion depends on particle size, $d$, the fraction of dust emitted must also depend on $d$. Thus, for a given soil, the particle size distribution of dust at emission (emission-dust PSD), $p_{\mathrm{s}}(d)$, must depend on saltation bombardment or on friction velocity, $u_{*}(\sqrt{\tau / \rho}$ with $\tau$ being surface shear stress

\footnotetext{
${ }^{1}$ The ratio $\gamma_{\mathrm{b}}=F / Q$ is a main issue in dust emission studies (Zender et al., 2003; Laurent et al., 2006). Marticorena et al. (1997) showed that $\gamma_{b}$ depends on soil clay content. Shao (2004) suggested that $\gamma_{\mathrm{b}}$ depends on friction velocity, soil type and soil particle size distribution.
} 
and $\rho$ being air density; see Sect. 4.1 for discussion). Alfaro et al. (1997) confirmed that $p_{\mathrm{s}}(d)$ depends on $u_{*}$ : as $u_{*}$ increases, $p_{\mathrm{s}}(d)$ shows a higher fraction of dust of smaller $d$. Based on this result and the observation that different laboratory techniques for PSD analysis yield profoundly different outcomes, depending on the disturbances applied to the samples (Fig. 1), Shao (2001) suggested to use a minimally disturbed PSD, $p_{\mathrm{m}}(d)$, as the limit of $p_{\mathrm{s}}(d)$ for weak saltation and a fully disturbed PSD, $p_{\mathrm{f}}(d)$, as the limit of $p_{\mathrm{s}}(d)$ for strong saltation. In this way, $p_{\mathrm{s}}(d)$ is expressed as a weighted average of $p_{\mathrm{m}}(d)$ and $p_{\mathrm{f}}(d)$

$p_{\mathrm{s}}(d)=\gamma p_{\mathrm{m}}(d)+(1-\gamma) p_{\mathrm{f}}(d)$,

where $0 \leq \gamma \leq 1$ is an empirical function of $u_{* \mathrm{t}}(d)$, which is the threshold friction velocity for particles of size $d$.

What is emission-dust PSD? We distinguish three closely related yet subtly different dust PSDs, namely, emissiondust PSD airborne-dust PSD, and emission-flux PSD. PSD of dust suspended in air (airborne-dust PSD) has been collected from different places under different conditions. Emissiondust PSD and airborne-dust PSD are identical if the latter is measured at dust source at height zero. Airborne-dust PSD can be used to approximate emission-dust PSD if it is measured close to the source and the dependency of particle motion in air on particle size can be neglected. For modelling size-resolved dust concentration in air (i.e. solving the dust concentration equation for different particle sizes), emissiondust PSD offers the Dirichlet-type boundary condition. If size-resolved dust-emission fluxes can be calculated, then we can specify the Neumann-type boundary condition for solving the dust concentration equation. From size-resolved dust-emission fluxes, an emission-flux PSD can be calculated (Sects. 2, 4.2). Emission-flux PSD is neither emissiondust nor airborne-dust PSD but describes how vertical dustconcentration gradient depends on particle size. In some earlier publications, unfortunately, the differences between the three dust PSDs are not clearly explained.

To our knowledge, emission-dust PSD has never been directly measured, but approximated using airborne-dust PSD measured at some, often different, heights (e.g. Kok, 2011b, Table S1). Available data of airborne-dust PSDs give the impression that they do not differ much. It has thus been suggested that airborne-dust PSDs may be "not so different" and hence emission-dust PSDs may also be not so different. Reid et al. (2008) stated that "on regional scales, common mode dust is not functionally impacted by production wind speed, but rather influenced by soil properties such as geomorphology". Kok (2011a, b) proposed a dust emission model by treating dust emission as a process of aggregate fragmentation by saltation bombardment. Since aggregate fragmentation is similar to brittle fragmentation, the size distribution produced in the process is scale invariant (Astrom, 2006). Kok (2011a, b) then proposed an emission-dust PSD and estimated its parameters from the data listed in Table S1 of Kok (2011b). The proposed emission-dust PSD is frequently used in dust models (Giorgi et al., 2012; Albani et al., 2014; Pisso et al., 2019). However, whether the not-so-different airbornedust PSDs justify "brittle fragmentation" as the underlying process for dust emission requires scrutiny.

Studies on dust PSD are yet to deliver definitive answers. The airborne-dust PSD measurements of Rosenberg et al. (2014) pointed to a larger fraction of fine particles than in earlier published data. Ishizuka et al. (2008) found that airborne-dust PSD measured close to surface depends on $u_{*}$ for a weakly crusted soil. Sow et al. (2009) examined the dependency of emission-flux PSD on $u_{*}$ for three dust events and reported that the PSD appeared to be independent of $u_{*}$ but differed significantly between weak and strong events. In line with Sow et al. (2009), Khalfallah et al. (2020) reported that emission-flux PSD depends on atmospheric boundarylayer (ABL) stability and attributed this to the dependency of particle diffusivity on particle size. They stated that the dependency of emission-dust PSD on $u_{*}$, as observed by Alfaro et al. (1997), may be of secondary importance in natural conditions compared to its dependency on ABL stability.

The argument of Khalfallah et al. (2020) rests on the preferential particle diffusion in turbulent flows. Csanady (1963) suggested that particle eddy diffusivity, $K_{\mathrm{p}}$, is related to eddy diffusivity, $K$, by

$K_{\mathrm{p}}=K\left(1+\beta^{2} w_{\mathrm{t}}^{2} / \sigma^{2}\right)^{-1 / 2}$,

where $\beta$ is a coefficient, $w_{\mathrm{t}}$ particle terminal velocity and $\sigma$ the standard deviation of (vertical) turbulent velocity. The analyses of Walklate (1987) and Wang and Stock (1993), among many others, reached similar conclusions. For dust particles smaller than $10 \mu \mathrm{m}, K_{\mathrm{p}} / K$ is close to one for $\sigma=$ $0.5 \mathrm{~m} \mathrm{~s}^{-1}$ and still larger than 0.95 for $\sigma=0.1 \mathrm{~m} \mathrm{~s}^{-1}$ (Shao, 2008; Fig. 8.12). Thus, preferential particle diffusion does not seem to fully explain the dependency of dust PSD on ABL stability.

The confusion with ground-emission-dust PSD prompted us to re-examine the data of Ishizuka et al. (2008) from the Japan Australian Dust Experiment (JADE). In JADE, airborne-dust PSDs were measured at small heights directly above the dust source and can be assumed to well approximate the emission-dust PSD. By composite analysis for different $u_{*}$ and ABL stabilities, we show that dust PSD depends on $u_{*}$, supporting the findings of Alfaro et al. (1997) and depends on ABL stability, which is consistent with the findings of Khalfallah et al. (2020). But in contrast to Khalfallah et al. (2020), we argue that these dependencies are not mutually exclusive but collectively point to the simple physics that emission-dust PSD is dependent on saltationbombardment intensity and efficiency.

\section{JADE data}

JADE was carried out during 23 February-14 March 2006 on an Australian farm at $\left(33^{\circ} 50^{\prime} 42.4^{\prime \prime} \mathrm{S}, 142^{\circ} 44^{\prime} 9.0^{\prime \prime} \mathrm{E}\right)$ 
(Ishizuka et al., 2008, 2014). The $4 \mathrm{~km}^{2}$ farmland was flat and homogeneous such that the JADE data are not affected by fetch. In JADE, atmospheric variables, land surface properties, soil PSD, size-resolved sand fluxes and dust concentrations were measured. Size-resolved dust-emission fluxes were estimated from the dust concentration measurements. Three sand particle counters (SPCs) (Mikami et al., 2005) were used to measure the sand fluxes in the size range of 39$654 \mu \mathrm{m}$ in 32 bins at $0.05,0.1$ and $0.3 \mathrm{~m}$ above ground at a sampling rate of $1 \mathrm{~Hz}$. Using the sand fluxes, $q_{j}(j=1,32)$, the PSD of saltation particles (saltation-flux PSD) is estimated for a particle size bin at $d_{j}$ with bin size $\Delta d_{j}$ as

$p\left(d_{j}\right) \Delta d_{j}=q_{j} / \sum_{j=1}^{j=32} q_{j}$.

Dust concentration was measured using optical particle counters (OPCs) for eight size groups: 0.3-0.6, 0.6-0.9, 0.9$1.4,1.4-2.0,2.0-3.5,3.5-5.9,5.9-8.4$ and $8.4-12.0 \mu \mathrm{m}$ at 1 , 2 and $3.5 \mathrm{~m}$ above ground. The upper size limit for the last bin is not well defined but set empirically to $12.0 \mu \mathrm{m}$ such that this bin can still be included in the analysis. Airbornedust PSD is estimated as

$p\left(d_{j}\right) \Delta d_{j}=c_{j} / \sum c_{j}$,

where $c_{j}$ denotes the dust concentration for size bin $j$. Similarly, the emission-flux PSD can be defined as

$p\left(d_{j}\right) \Delta d_{j}=F_{j} / \sum F_{j}$,

where $F_{j}$ denotes the dust flux for size bin $j$. It should be noted that the emission-flux PSD describes how the covariance of particle velocity and particle concentration depends on particle size not the concentration itself. In this study, we use the airborne-dust PSD observed at $1 \mathrm{~m}$ to approximate emission-dust PSD and use the airborne-dust PSD observed at $3.5 \mathrm{~m}$ and the emission-flux PSD derived from the $3.5 \mathrm{~m}$ and $1 \mathrm{~m} \mathrm{OPC}$ measurements for additional discussions (Sect. 4.2). Hereafter, emission-dust PSD approximated using the $1 \mathrm{~m} \mathrm{OPC}$ airborne-dust PSD is simply referred to as dust PSD unless otherwise stated.

Atmospheric variables, including wind speed, air temperature and humidity at various levels, radiation, and precipitation were measured using an automatic weather station. These quantities were sampled at $5 \mathrm{~s}$ intervals and their $1 \mathrm{~min}$ averages were recorded (see Sect. 4.2 for discussions). Two anemometers mounted at 0.53 and $2.16 \mathrm{~m}$ measured wind speed. From the atmospheric data, the Obukhov length, $L$; sensible heat flux, $H$; and friction velocity, $u_{*}$, were derived. ${ }^{2}$ Also measured were soil temperature and moisture.

\footnotetext{
${ }^{2}$ Drag-partition theory (Raupach, 1992; Webb et al., 2019) tells us that shear stress, $\tau=\rho u_{*}^{2}$, is not the same as the shear stress, $\tau_{\mathrm{s}}$, experienced by soil particles, due to roughness sheltering. For
}

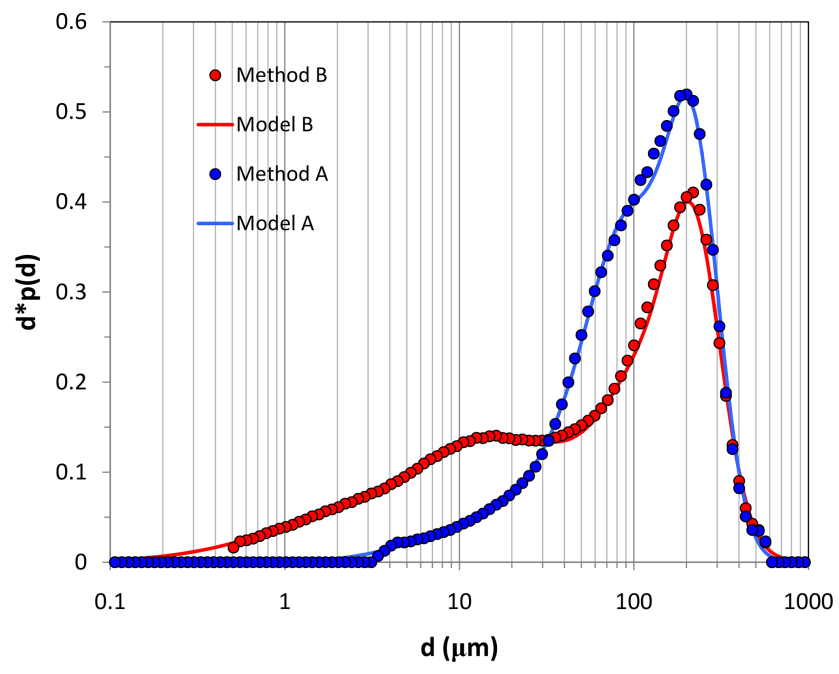

Figure 1. Soil particle-size distribution obtained using Method A and Method B, together with the respective approximations (Model A and Model B).

Surface soil samples were taken and soil PSD was analysed in the laboratory using Method A and Method B with a particle size analyser (Microtrac MT3300EX, Nikkiso). In Method A, water was used for sample dispersion with no ultrasonic action. In Method B, sodium hexametaphosphate (HMP) $0.2 \%$ solution was used for sample dispersion and $1 \mathrm{~min}$ ultrasonic action of $40 \mathrm{~W}$ was applied. Following the convention of sedimentology, the soil is a sandy loam based on the analysis using Method B. Figure 1 shows $p_{\mathrm{A}}(d)$ (soil PSD from Method A) and $p_{\mathrm{B}}(d)$ (soil PSD from Method B) and the corresponding approximations: $p_{\mathrm{A}}$ shows a larger fraction of particles in the range of 30-300 $\mu \mathrm{m}$, while $p_{\mathrm{B}}$ a larger fraction of particles in the range of $0.1-30 \mu \mathrm{m}$.

An overview of the JADE data is shown in Fig. 2. During the experiment, 12 significant aeolian events were recorded, as marked in the figure. Most of the events occurred under unstable ABL conditions. Several quantities can be used as a measure of ABL stability, but the one used here is the convective scaling velocity, $w_{*}$, defined as

$w_{*}=\left(\frac{g}{\bar{\theta}} H_{0} z_{l}\right)^{\frac{1}{3}}$

where $g / \bar{\theta}$ is the buoyancy parameter with $g$ being the acceleration due to gravity and $\bar{\theta}$ the mean potential temperature; $H_{0}$ is surface kinematic heat flux $\left(\mathrm{Km} \mathrm{s}^{-1}\right)$ and $z_{l}$ a scaling length (set to the capping inversion height for convective $\mathrm{ABL}$ and $100 \mathrm{~m}$ for stable $\mathrm{ABL}$ ). For unstable conditions, $w_{*}$ is positive, while for stable conditions $w_{*}$ is negative. The reason for choosing $w_{*}$ is that it is a scaling parameter for

JADE, the surface is bare and thus the effect of roughness sheltering is neglected. The saltation fluxes used in this study are measured and do not involve the assumption $\tau=\tau_{\mathrm{S}}$ or otherwise. 
the strength of turbulence. Usually, $w_{*}$ is not used for stable ABLs but used here as an indicator for the suppression of turbulence by negative buoyancy.

In addition to the 12 events, a number of weak and intermittent events occurred. In this study, we first use the whole dataset for the dust-PSD analysis, and then we use the data for Event-10, Event-11 and Event-12 for case studies. These three events are chosen so that Event-10 is the strongest event during JADE, Event-11 is one that occurred at night under stable conditions, and Event-12 occurred with a weakly crusted soil surface (Ishizuka et al., 2008).

\section{Results}

\subsection{Overall results}

Plotted in Fig. 3 are the time series of dust PSD for the entire JADE period, which show rich temporal variations apart from, probably, Event-10. To examine dust-PSD dependency on friction velocity, we use $u_{*}$ to denote the $1 \mathrm{~min}$ values of friction velocity, $p\left(u_{*}\right)$ its probability density function (PDF), $\bar{u}_{*}$ its mean and $\sigma_{u *}$ its standard deviation. The $u_{*}$ values are divided into the categories of $0-0.25,0.25-0.35$, $0.35-0.45$ and $0.45-0.55 \mathrm{~m} \mathrm{~s}^{-1}$, and the corresponding dust PSDs and saltation PSDs are sorted accordingly. These $u_{*}$ categories correspond roughly to intermittent, weak, moderate and strong saltation, respectively. The threshold friction velocity, $u_{*}$, for the JADE site is around $0.2 \mathrm{~m} \mathrm{~s}^{-1}$, but intermittent saltation has been observed often at $u_{*}$ below this $u_{* \mathrm{t}}$. The dust PSDs are then composite averaged for the $u_{*}$ categories. Figure 4a shows the dust PSDs for the different $u_{*}$ categories and the mean dust PSD averaged over all $u_{*}$ categories (including a total of $156341 \mathrm{~min}$ points). We have repeated the same averaging procedure using a subset of the JADE data, conditioned with $Q>0.1 \mathrm{~g} \mathrm{~m}^{-1} \mathrm{~s}^{-1}$, and found that the results are very similar to those presented in Fig. 4. The mean dust PSD shows an interesting local minimum at $\sim 4 \mu \mathrm{m}$. This is attributed to the lack of particles of this size in the $u_{*}<0.25 \mathrm{~m} \mathrm{~s}^{-1}$ category. Figure 4a shows that dust PSD clearly depends on $u_{*}$, particularly in the size range $2-10 \mu \mathrm{m}$. In general, as $u_{*}$ increases, the fraction of fine dust particles increases. For the submicron size range, the dependency of dust PSD on $u_{*}$ is less definitive. The dust PSD for the $u_{*}<0.25 \mathrm{~m} \mathrm{~s}^{-1}$ category shows a higher fraction of submicron dust particles, especially in stable conditions (Fig. 4b). Apart from this, the results shown in Fig. 4a are consistent with the findings of Alfaro et al. (1997) that dust PSD is $u_{*}$ dependent.

To examine the dust PSD dependency on ABL stability, we divide the dataset into stable $\left(w_{*}<0\right)$, moderately unstable $\left(0 \leq w_{*}<1 \mathrm{~m} \mathrm{~s}^{-1}\right)$ and unstable $\left(w_{*} \geq 1 \mathrm{~m} \mathrm{~s}^{-1}\right)$ stability classes. For each stability class, the dust PSD data are regrouped according to the $u_{*}$ categories. Figure $4 \mathrm{~b}$ shows the dust PSDs averaged for different $u_{*}$ categories and stabil- ity classes. For given stability class, dust PSD shows dependency on $u_{*}$, and for a given $u_{*}$ category, dust PSD shows dependency on $w_{*}$. For given $u_{*}$, the mode of dust PSD shifts systematically to finer particles as the ABL becomes more unstable.

\subsection{Case study results}

We now study the cases of Event-10 (09:49-19:13 LT 12 March 2006; Julian day 70.9506940-71.3423611) (note that all times are given in UTC unless explicitly stated as LT), Event-11 (21:12 LT 12 March-02:08 13 March 2006, Julian day 71.42500-71.63056) and Event-12 (09:54-18:58 LT 13 March 2006, Julian day 71.95417-72.33194). Figure 5 shows the $1 \mathrm{~min}$ averages of wind speed at $0.53 \mathrm{~m}, U$, air temperature at $0.66 \mathrm{~m}, T$, saltation flux at $0.05 \mathrm{~m}, q_{5} \mathrm{~cm}$ and dust concentration (summed over all particle size bins) at $1 \mathrm{~m}, C_{1 \mathrm{~m}}$. Event-10 occurred under daytime unstable conditions. It was a very hot day prior to a cool change (cold front causing temperature drop but no rainfall), with near-surface air temperature reaching $52^{\circ} \mathrm{C}$ and wind speed $\sim 8 \mathrm{~m} \mathrm{~s}^{-1}$. The event lasted $\sim 10 \mathrm{~h}$. The cool change occurred at $\sim$ 19:00-21:00 LT 13 March 2006. While precipitation was not recorded by the rain gauge (with resolution of $0.2 \mathrm{~mm}$ ), the rain sensor (PPS-01(C-PD1), Prede Co. Ltd.), as marked in Fig. 5b, sensed an event of raindrops shortly before the cool change, lasting about $2 \mathrm{~min}$, and shortly after, lasting about 1 min (Ishizuka et al., 2008). The strong winds (probably also strong sand drift and dust emission) accompanying the cool change caused the shutdown of the instruments and thus, unfortunately, this period was not fully recorded. Event-11 occurred under stable conditions after the cool change in the night time of 12/13 March 2006, during which $T$ was dropping from $\sim 40$ to $\sim 33^{\circ} \mathrm{C}$ and $U$ from $\sim 8$ to $\sim 5 \mathrm{~m} \mathrm{~s}^{-1}$. Event-11, which can also arguably be considered to be part of Event-10, was much weaker than Event-10.

As the OPC measurements were taken close to the surface and directly above the dust source, the dust-concentration values were generally high. The mean, standard deviation, maximum and minimum of $C_{1 \mathrm{~m}}$ are respectively 7.56, 8.56, 65.96 and $0.02 \mathrm{mg} \mathrm{m}^{-3}$ for Event-10 and are 3.05, 10.57, 100.17 and $0.04 \mathrm{mg} \mathrm{m}^{-3}$ for Event-11. The extremely high dust concentrations measured shortly before and after the cool change could be affected by dust advection and are excluded from the analysis (although their inclusion made no difference to the event averages of the dust PSDs). For other times, it can be safely assumed that the dust observed was locally emitted.

Event- 12 is developed shortly after the weak rainfall event (R4). Again, while precipitation was not recorded by the rain gauge (i.e. the total rainfall was less than $0.2 \mathrm{~mm}$ ), the rain sensor reported rain drops during 71.70625-71.95278. Ishizuka et al. (2008) reported that Event-12 is unique for JADE, because it is the only case when the soil surface was weakly crusted. We will show later how dust PSD can sub- 


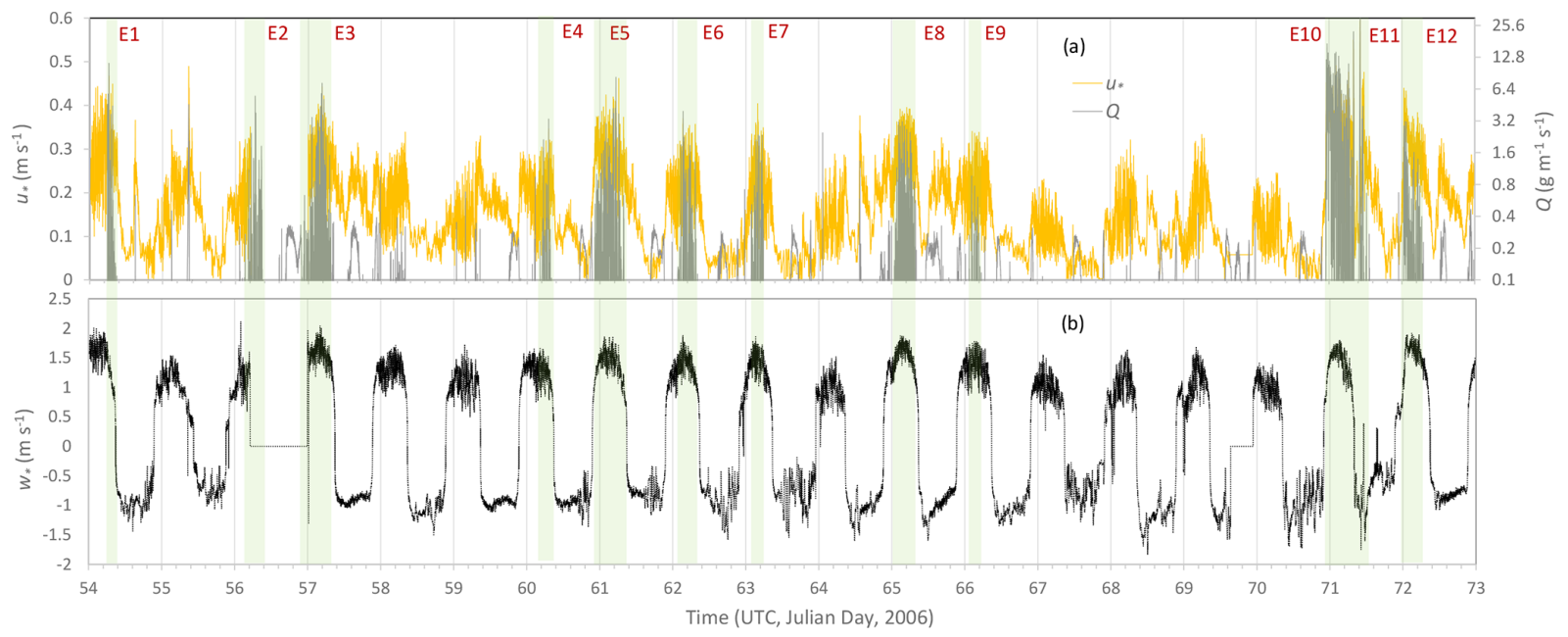

Figure 2. (a) One-minute averaged friction velocity, $u_{*}$, and streamwise saltation flux, $Q$, for the JADE observation time period; (b) 1 min averaged convective scaling velocity, $w_{*}$. In addition to the 12 aeolian events marked, a number of weaker and intermittent aeolian events occurred.

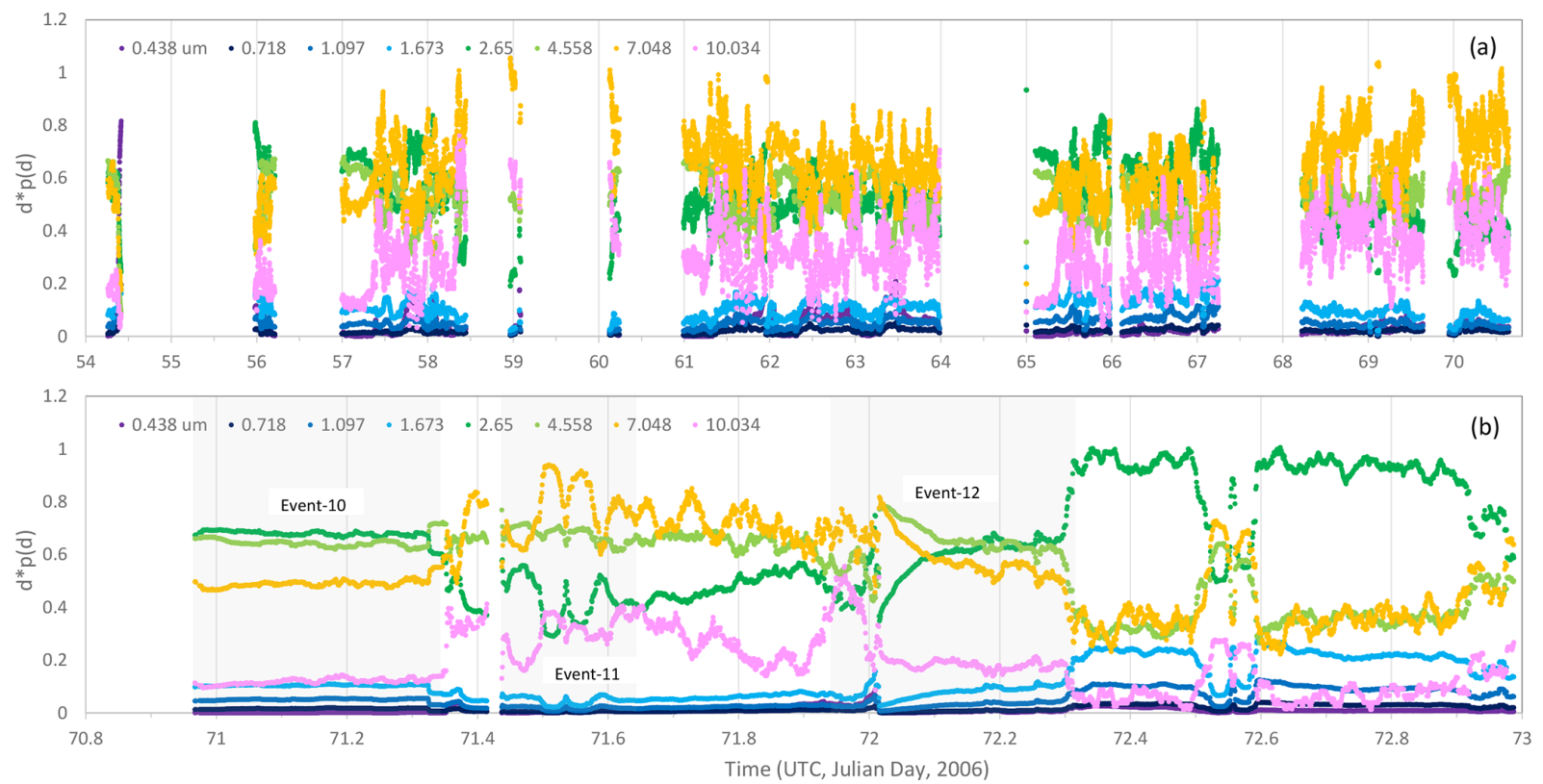

Figure 3. Dust PSD measured at $1 \mathrm{~m}$ using OPC for the entire JADE observation period plotted in two sections: (a) for section Julian day 54-70.8 and (b) for section Julian day 70.8-73.0.

stantially evolve even within one dust event, as soil surface conditions change (Fig. 10).

Figure 6 shows the dust PSDs for the different $u_{*}$ categories for Event-10, Event-11 and Event-12. For Event-11 and Event-12, the dependency of dust PSD on $u_{*}$ is obvious, in agreement with the overall results shown in Fig. 4a. The dust PSD for Event-10 shows no clear dependency on $u_{*}$, which was reported in Shao et al. (2011). Our basic argument for dust PSD dependency on $u_{*}$ rests upon the assumption that saltation-impact speed is $u_{*}$ dependent. It has been suggested that impact-particle speed may not strongly depend on $u_{*}$ for transport-limited saltation (Ungar and Haff, 1987), because particle-flow feedbacks force an approximately constant saltation-impact speed. While this argument is supported by some experimental evidence (Martin and Kok, 2017) and numerical simulations (Duran et al., 2012; Kok et al., 2012), its general validity and the conditions for its validity need further examination. JADE Event-10 is probably a case which comes closest to meet the requirements of strong particle-flow feedback and sustained equilibrium of saltation for the Ungar and Haff (1987) hypothesis to apply. In addition, Event-10 occurred on an extremely hot and dry day, 

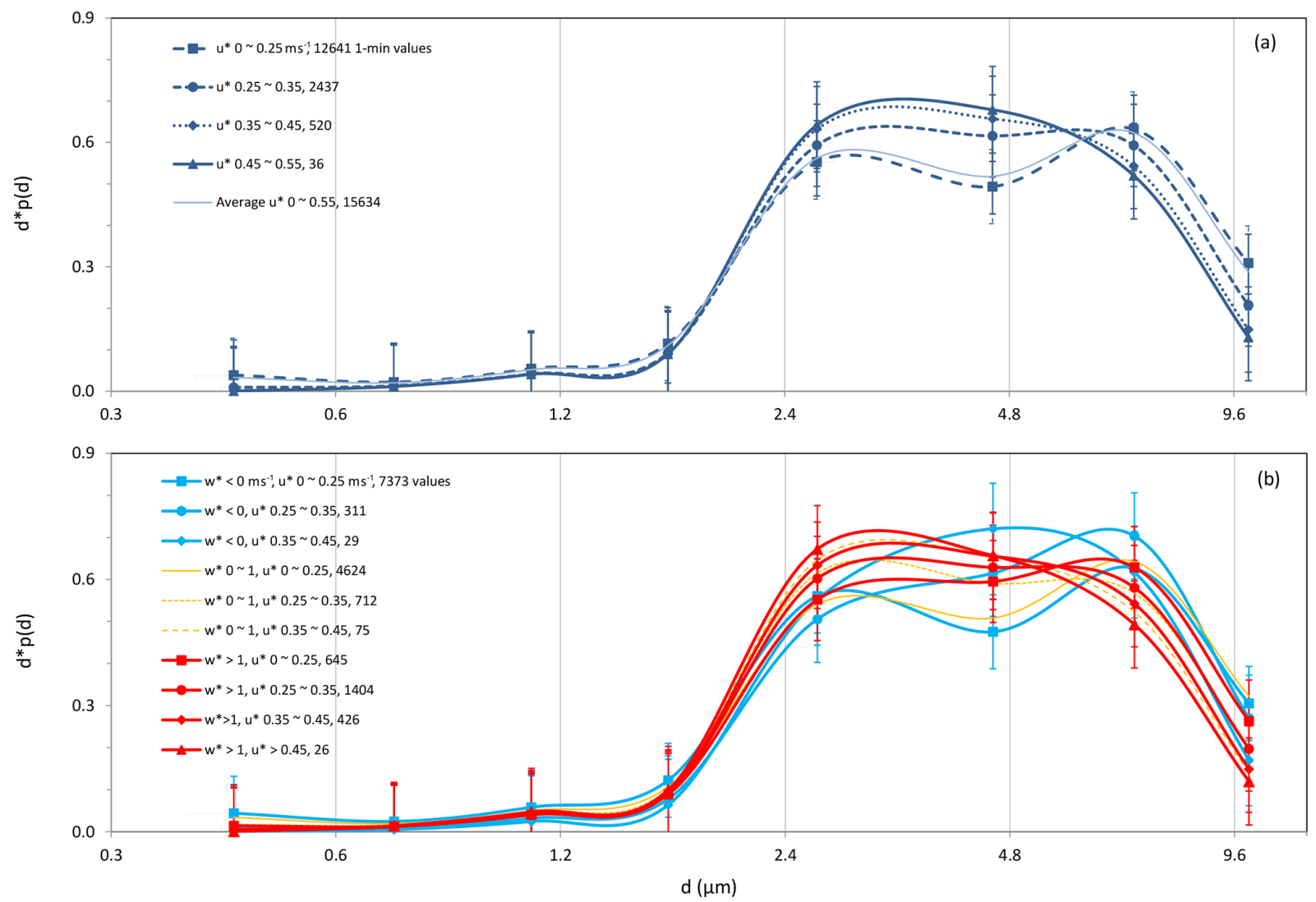

Figure 4. (a) Dust PSD for different $u_{*}$ categories derived from the whole JADE dataset; (b) same as (a) but for the different $u_{*}$ categories under stable $\left(w_{*}<0\right)$, moderately unstable $\left(0 \leq w_{*}<1 \mathrm{~m} \mathrm{~s}^{-1}\right)$ and unstable $\left(w_{*} \geq 1 \mathrm{~m} \mathrm{~s}^{-1}\right)$ conditions.

with the $0.66 \mathrm{~m}$ air temperature reaching $\sim 52^{\circ} \mathrm{C}$ and relative humidity below $3 \%$. It is likely that under such extreme conditions, inter-particle cohesion is destroyed. These factors combined may be responsible for the lack of dust PSD dependency on $u_{*}$ for Event-10 (Fig. 6). But for all other JADE events, the dependency of dust PSD on $u_{*}$ is significant.

The event-averaged dust PSDs for Event-10, Event-11 and Event- 12 clearly differ. The mean and standard deviation of $u_{*}$ and $w_{*}$ were respectively 0.36 and $0.057 \mathrm{~m} \mathrm{~s}^{-1}$ and 1.03 and $0.29 \mathrm{~m} \mathrm{~s}^{-1}$ for Event-10; they were respectively 0.28 and $0.077 \mathrm{~m} \mathrm{~s}^{-1}$ and -0.41 and $0.159 \mathrm{~m} \mathrm{~s}^{-1}$ for Event-11. From Event-10 to Event-11, the dust PSD mode shifted from about 3 to $6 \mu \mathrm{m}$. During Event-10, a substantially higher fraction of particles in the size range of $0.4-4 \mu \mathrm{m}$ existed. To further examine how dust PSD depends on saltation intensity, we have averaged the dust PSDs for different $Q$ categories (not shown). It is found that weak saltation corresponded to coarser dust particles and strong saltation to finer dust particles. Figure 6 confirms the dependency of dust PSD on ABL stability, consistent with the overall results shown in Fig. 4.

Figure $5 \mathrm{~b}$ shows that the wind conditions for Event- 10 and Event-12 were not too different, but Event-12 was much weaker. Figure 6 shows that also the dust PSDs for the two events considerably differ, with Event- 10 being the one with richer finer dust particles. Event-12 will be further discussed in Sect. 4.2.

We make the following observations based on the JADE data: (1) dust PSD has rich temporal variations and is not "universal"; (2) dust PSD depends on $u_{*}$ and ABL stability; and (3) dust PSD is influenced by soil surface conditions. These observations support the conceptual understanding that dust PSD is determined both by saltation bombardment and by soil binding strength (Shao, 2001, 2004).

\section{Discussions}

\subsection{Influence of turbulence on dust PSD}

The reason for the dependency of dust PSD on $u_{*}$ has been explained in Gillette et al. (1974), Gillette (1981), Shao et al. (1993), Alfaro et al. (1997) and Shao (2001, 2004), because $u_{*}$ is a descriptor of saltation-bombardment intensity. In the earlier explanations, only mean friction velocity and mean saltation are considered, while the turbulent nature of saltation bombardment is implicitly neglected. But how is the dependency of dust PSD on ABL stability, here $w_{*}$, explained? The most conspicuous reason is the enhanced saltation bombardment by turbulence in unstable conditions. 

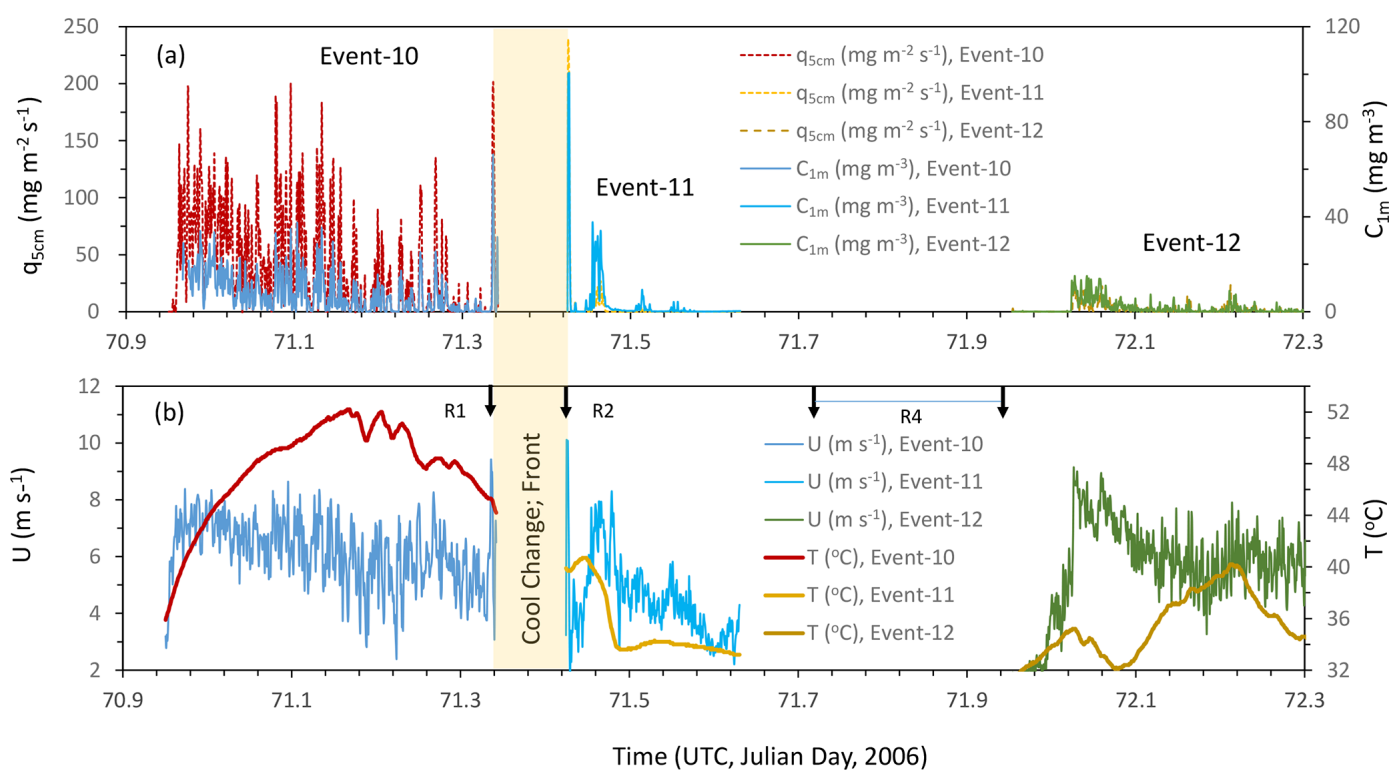

Figure 5. (a) One-minute averaged saltation flux at $0.05 \mathrm{~m}, q_{5 \mathrm{~cm}}$, and dust concentration at $1 \mathrm{~m}, C_{1} \mathrm{~m}$, for Event-10, Event-11 and Event-12; (b) same as (a) but for wind speed at $0.53 \mathrm{~m}$ above ground, $U$, and air temperature at $0.66 \mathrm{~m}, T$. The cool change is marked and the three rain events sensed by the rain sensor are marked as $\mathrm{R} 1, \mathrm{R} 2$ and $\mathrm{R} 4$ using the black arrows.

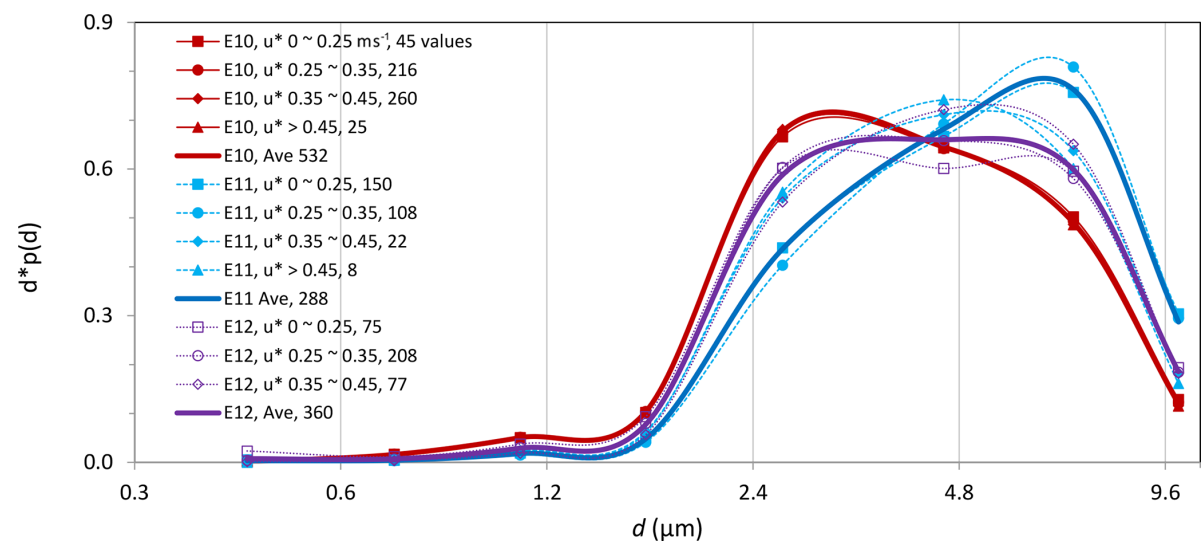

Figure 6. Dust PSD for different $u_{*}$ categories for Event-10, Event-11 and Event-12. Also shown are the PSDs averaged over all $u_{*}$ categories for the individual events.

It is interesting to examine how dust PSD is related to saltation PSD. The saltation PSD for Event-10 and Event-11 are shown in Fig. 7. First, for $u_{*} \leq 0.25 \mathrm{~m} \mathrm{~s}^{-1}$ in Event-11, saltation PSD was confined to a narrow size range centred at $70-80 \mu \mathrm{m}$ where $u_{* \mathrm{t}}$ is minimum. This indicates that saltation splash or bombardment was weak to mobilize particles in other size ranges. In contrast, for $u_{*} \leq 0.25 \mathrm{~m} \mathrm{~s}^{-1}$ in Event10, saltation PSD covered a broader size range, implying that saltation splash was strong to entrain particles of other sizes. Second, for both Event-10 and Event-11, the peak values of saltation PSD were shifted to larger particles for larger $u_{*}$ : for Event-10 the peak for $0.25<u_{*} \leq 0.35 \mathrm{~m} \mathrm{~s}^{-1}$ was at $203.3 \mu \mathrm{m}$, while for $0.45<u_{*} \leq 0.55 \mathrm{~m} \mathrm{~s}^{-1}$ it was at $257.8 \mu \mathrm{m}$. Clearly, since $u_{* \mathrm{t}}$ is particle size dependent, salta- tion PSD is a selective sample of the soil PSD by wind. Third, the saltation PSDs for given $u_{*}$ categories (e.g. $0.35<u_{*} \leq$ $0.45 \mathrm{~m} \mathrm{~s}^{-1}$, Fig. 8a and b) differed significantly between Event-10 and Event-11 as a consequence of ABL stability. In Event-11 (Fig. 8a), saltation was not fully developed, as the saltation PSD plateau in the size range 100-300 $\mu \mathrm{m}$ suggests, implying that saltation splash or bombardment was not efficient. In Event-10 (Fig. 7b), saltation was more fully developed.

The stronger saltation of Event-10 is partially attributed to the stronger wind and instability, which result in a larger $\bar{u}_{*}$ than in Event-11. It is known from the ABL similarity theory 

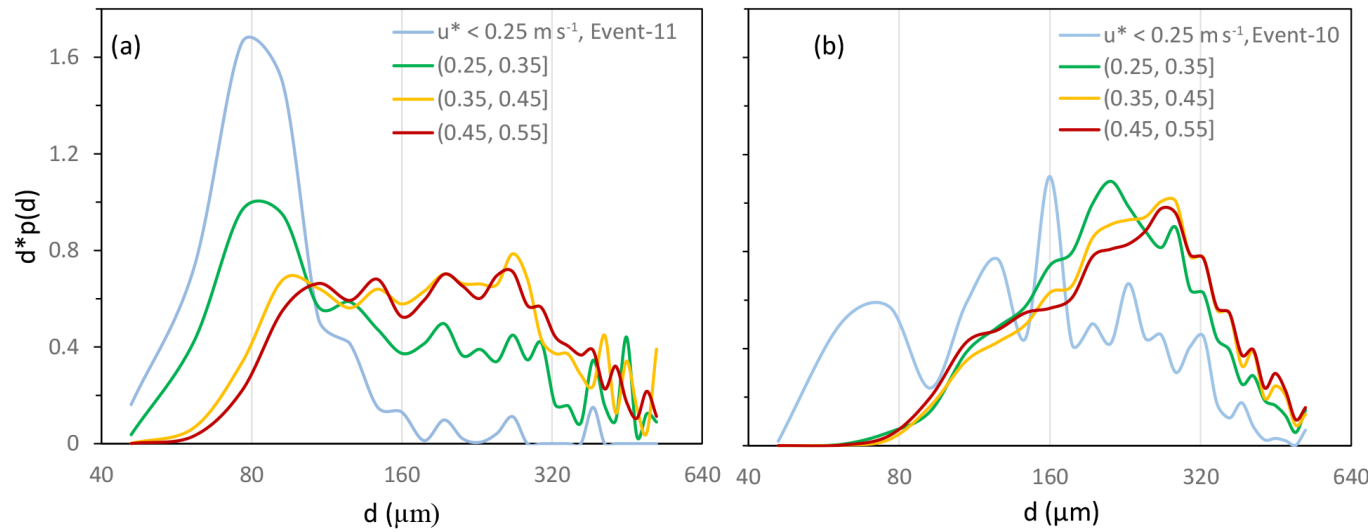

Figure 7. (a) Saltation PSD averaged for four different $u_{*}$ categories for Event-11; (a) same as (a) but for Event-10.

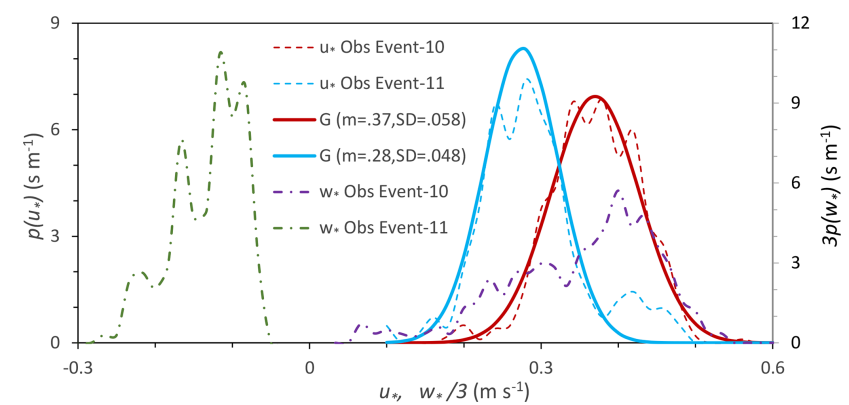

Figure 8. The probability density functions of $u_{*}$ and $w_{*}, p\left(u_{*}\right)$ and $p\left(w_{*}\right)$ for Event-10 and Event-11, together with the Gaussian approximations for the $p\left(u_{*}\right)$ functions. The mean values $(\mathrm{m})$ and standard deviations (SD) for the Gaussian (G) distributions are given. Note that for $p\left(w_{*}\right), 3 p\left(w_{*}\right)$ against $w_{*} / 3$ is plotted to conveniently present the information in the same graph.

that

$\bar{u}_{*}=\frac{k z}{\phi_{\mathrm{m}}} \frac{\partial \bar{u}}{\partial z}$

where $\kappa$ is the von Karman constant, $z$ height and $\phi_{m}$ a similarity function (Stull, 1988):

$\phi_{\mathrm{m}}=\left\{\begin{array}{ccc}1+\beta_{\mathrm{m}} \zeta & \zeta>0 & \text { stable } \\ \left(1-\gamma_{\mathrm{m}} \zeta\right)^{1 / 4} & \zeta<0 & \text { unstable } \\ 1 & \zeta=0 & \text { neutral }\end{array}\right.$

where $\zeta=z / L$ ( $L$ is Obukhov length), $\beta_{\mathrm{m}}=5$ and $\gamma_{\mathrm{m}}=16$ are empirical coefficients (Businger et al., 1971). For stable conditions $\phi_{\mathrm{m}}>1$ and for unstable conditions $\phi_{\mathrm{m}}<1$. Figure 8 shows the PDFs of $u_{*}$ and $w_{*}$ for Event-10 and Event-11 together with the approximations for the PDFs of $u_{*}$. For Event-10, $\bar{u}_{*}=037 \mathrm{~m} \mathrm{~s}^{-1}$, while for Event-11 $\bar{u}_{*}=$ $028 \mathrm{~m} \mathrm{~s}^{-1}$.

We suggest that the dependency of dust PSD on $w_{*}$ for given $u_{*}$ is attributed to saltation-bombardment intensity from two perspectives. First, as Fig. 8 shows, $u_{*}$ is a stochastic variable. Li et al. (2020) suggested that $\tau=\rho u_{*}^{2}$ in neutral conditions is Gauss distributed. Klose et al. (2014) reported that $\tau$ in unstable conditions is Weibull distributed. The exact form of $p(\tau)$ requires further investigation, but the JADE data of $u_{*}$ show that $p\left(u_{*}\right)$ is reasonably Gaussian. Hence

$p(\tau)=\frac{1}{2 \rho u_{*}} p\left(u_{*}\right)$

is skewed to smaller $\tau$, suggesting that the large-eddy model results of Klose et al. (2014) are qualitatively reasonable. Figure 8 shows that $u_{*}$ in Event-10 not only had a larger mean value but also a larger variance than in Event-11. We emphasize that the variance of $u_{*}$ strongly affects saltation, because saltation flux depends non-linearly on $u_{*}$. To illustrate this, we consider $u_{* 1}$ and $u_{* 2}$ and assume that

- $u_{* 1}$ and $u_{* 2}$ are Gaussian distributed and have the same mean that equals $u_{* \mathrm{t}}\left(\right.$ say $\left.0.2 \mathrm{~m} \mathrm{~s}^{-1}\right)$;

- $u_{* 1}$ and $u_{* 2}$ have respectively standard deviations, $\sigma_{1}$ and $\sigma_{2}$, with $\sigma_{2}=\eta \sigma_{1}$ and $\eta>1$; and

- $Q$ satisfies the Owen's model (Owen, 1964),

$Q_{i}=c u_{* i}^{3}\left(1-\frac{u_{* t}^{2}}{u_{* i}^{2}}\right)$

for $u_{*}>u_{* t}$,

otherwise 0 ; with $i=1,2$;

where $c$ is a dimensional constant. It follows that the ratio of the mean values of $Q_{2}$ and $Q_{1}$ is

$\eta_{Q}=\frac{\bar{Q}_{2}}{\bar{Q}_{2}}=\int_{u * t}^{\infty} Q_{2} p\left(u_{* 2}\right) d u_{* 2} / \int_{u * t}^{\infty} Q_{1} p\left(u_{* 1}\right) d u_{* 1}$. 
Table 1. Streamwise saltation flux ratios, $\eta_{Q}$, for different $u_{*} \mathrm{SD}$ ratios, $\eta$ (see text for details).

\begin{tabular}{lrrrrrrr}
\hline$\eta_{1}$ & 1.2 & 1.4 & 1.6 & 1.8 & 2 & 3 & 4 \\
$\eta_{Q}$ & 1.30 & 1.63 & 2.00 & 2.41 & 2.86 & 5.83 & 10.15 \\
\hline
\end{tabular}

Equation (9) can be evaluated numerically for different $\eta$ (Table 1) and is approximately

$\eta_{Q}=0607 \eta^{2}-00028 \eta+04283$.

This shows that $p\left(u_{*}\right)$ profoundly influences the magnitude of $Q$. For fixed $\bar{u}_{*}$, a larger $u_{*}$ variance corresponds to a larger $\bar{Q}$.

Second, in unstable conditions, turbulence is stronger due to buoyancy production, which leads to increased saltationbombardment intensity. We do not have independent evidence to verify this, but to illustrate the point, we use a twodimensional (2D, $x_{1}$ in mean wind direction and $x_{3} \equiv z$ in vertical direction) saltation model (Supplement A) to simulate the impact kinetic energy of saltation sand grains. For given $u_{*}$ and roughness length, $z_{0}$, a $2 \mathrm{D}$ turbulent flow is generated with the mean wind assumed to be logarithmic $\kappa \overline{u_{1}}=\overline{u_{*}} \ln \left(z / z_{0}\right)$; the velocity standard deviations satisfy

$$
\begin{aligned}
\frac{\sigma_{u 1}}{\bar{u}_{*}} & =a \cdot \ln \left(\frac{z}{z_{0}}\right), \\
\frac{\sigma_{u 3}}{\bar{u}_{*}} & =f_{u 3}(\zeta) \cdot a \cdot \ln \left(\frac{z}{z_{0}}\right) ;
\end{aligned}
$$

and the dissipation rate for turbulent kinetic energy, $\varepsilon$, satisfies

$\varepsilon \frac{\kappa z}{\bar{u}_{*}^{3}}=f_{\varepsilon}(\zeta)$.

The similarity relationships $f_{u 3}(\zeta)$ and $f_{\varepsilon}(\zeta)$ follow Kaimal and Finnigan ( $\mathrm{p} \mathrm{16}, 1995)$. As saltation takes place in the layer close to the surface, the vertical profiles of $\sigma_{u 1}$ and $\sigma_{u 3}$ are considered following Yahaya et al. (2003). The coefficient $a$ (where $a=1.16 \beta$ ) is varied by setting $\beta$ to $0.75,1.00$ or 1.25 for weak, normal or strong turbulence, respectively.

In each numerical experiment, 20000 sand grains of identical size are released from the surface and their trajectories are computed. At impact on the surface, the particles rebound with a probability of 0.95 and a rebounding kinetic energy, $K_{\text {reb }}, 0.5$ times the impact kinetic energy, $K_{\text {imp. }}$. The rebound angle is Gauss distributed with a mean of $40^{\circ}$ and standard deviation $5^{\circ}$. Splash entrainment is neglected. The PDF of $K_{\mathrm{imp}}, p\left(K_{\mathrm{imp}}\right)$, is used as a measure for bombardment intensity.

Many numerical experiments were carried out, but for our purpose, we show only the results of the ones listed in Table 2. The initial velocity components of sand grains $\left(V_{1 o}, V_{30}\right)$ are generated stochastically. $V_{10}$ is Gauss distributed with a mean $\bar{V}_{1 \mathrm{o}}=\bar{u}_{*} \cos \left(55^{\circ}\right)$ and standard deviation, $\sigma_{V 1 \mathrm{o}}=0.1 \bar{u}_{*} ; V_{3 \mathrm{o}}$ is Weibull distributed with
Table 2. Numerical experiments for saltation-bombardment intensity. For all experiments, $z_{0}=0.48 \mathrm{~mm}, C_{0}=5, C_{1}=2$ and $\rho_{\mathrm{p}}=$ $2650 \mathrm{~kg} \mathrm{~m}^{-3}$.

\begin{tabular}{lrrrr}
\hline Experiment & $u_{*}\left(\mathrm{~m} \mathrm{~s}^{-1}\right)$ & $L(\mathrm{~m})$ & $d(\mu \mathrm{m})$ & $\beta$ \\
\hline Exp1a, 1b, 1c & 0.35 & $\infty, 30,-9$ & 100 & 1.0 \\
Exp2a, 2b & 0.35 & 30 & 200 & $0.75,1$ \\
Exp2c & 0.35 & -9 & 200 & 1.25 \\
Exp3a, 3b & $u_{2 \mathrm{~m}}=7.3$ & $H=-100 ;$ & 200 & 1 \\
& & $400 \mathrm{~W} \mathrm{~m}^{-2}$ & & \\
\hline
\end{tabular}

a shape parameter $A=2$ and a scale parameter $B^{\prime}=$ $\bar{u}_{*} \sin \left(55^{\circ}\right) / \Gamma(1+1 / A)$, where $\Gamma$ is a gamma function. To account for the influence of stability on $V_{30}, B^{\prime}$ is modified such that the adjustment to $\sigma_{V 3}$ is the same as that to $\sigma_{u 3}\left(10 z_{0}\right)$; that is, the modified scale parameter, $B$, is given by

$B=\beta f_{u 3}\left(\frac{10 z_{0}}{L}\right) B^{\prime}$.

Figure 9a compares $p\left(K_{\text {imp }}\right)$ for Exp1a, $1 \mathrm{~b}$ and 1c and shows that $p\left(K_{\mathrm{imp}}\right)$ for these cases is very similar. The small differences in $p\left(K_{\text {imp }}\right)$ between the cases suggest that the differences in particle trajectory arising from the stability modification to turbulence profile, with $u_{*}$ fixed, are negligible. However, a small change in $\beta$, as Fig. 9b shows for Exp2a, $2 \mathrm{~b}$ and $2 \mathrm{c}$, can lead to significant changes in $p\left(K_{\text {imp }}\right)$ with larger $\beta$ corresponding to higher probability of larger $K_{\text {imp }}$, namely, high saltation-bombardment intensity. In Exp3a and $3 \mathrm{~b}, u_{2} \mathrm{~m}$ (mean wind $2 \mathrm{~m}$ height) is set to $7.3 \mathrm{~m} \mathrm{~s}^{-1}$ and the surface sensible heat flux, $H$, to -100 and $400 \mathrm{~W} \mathrm{~m}^{-2}$. Figure $9 \mathrm{c}$ shows that $p\left(K_{\mathrm{imp}}\right)$ differs with larger $K_{\text {imp }}$ in unstable conditions.

To summarize, the numerical experiments suggest that the PDF of the particle initial velocity significantly influences the saltation-bombardment intensity, and saltating particles in unstable $\mathrm{ABL}$ impact the surface with larger kinetic energy than in stable ABL. This is the result seen in Figs. 7 and 8; i.e. saltation in Event-10 was more fully developed than in Event-11. The more fully developed saltation in unstable ABL increases saltation-bombardment intensity and hence the release of finer dust particles, as seen in Fig. 6.

\subsection{Influence of surface condition on dust PSD}

A detailed analysis of Event-12 (Fig. 10) reveals that the dependency of dust PSD on friction velocity and ABL stability is made complicated by soil surface conditions. To analyse how dust PSD evolved during the event, we divide Event-12, which lasted $\sim 5.5 \mathrm{~h}$, into 11 half-hourly time sections labelled as S1, S2, etc. For each section, the dust PSD is averaged over time and plotted in Fig. 10c. Figure 10a shows the time series of $Q, w_{*}$ and $u_{*}$, and Fig. 11b those 

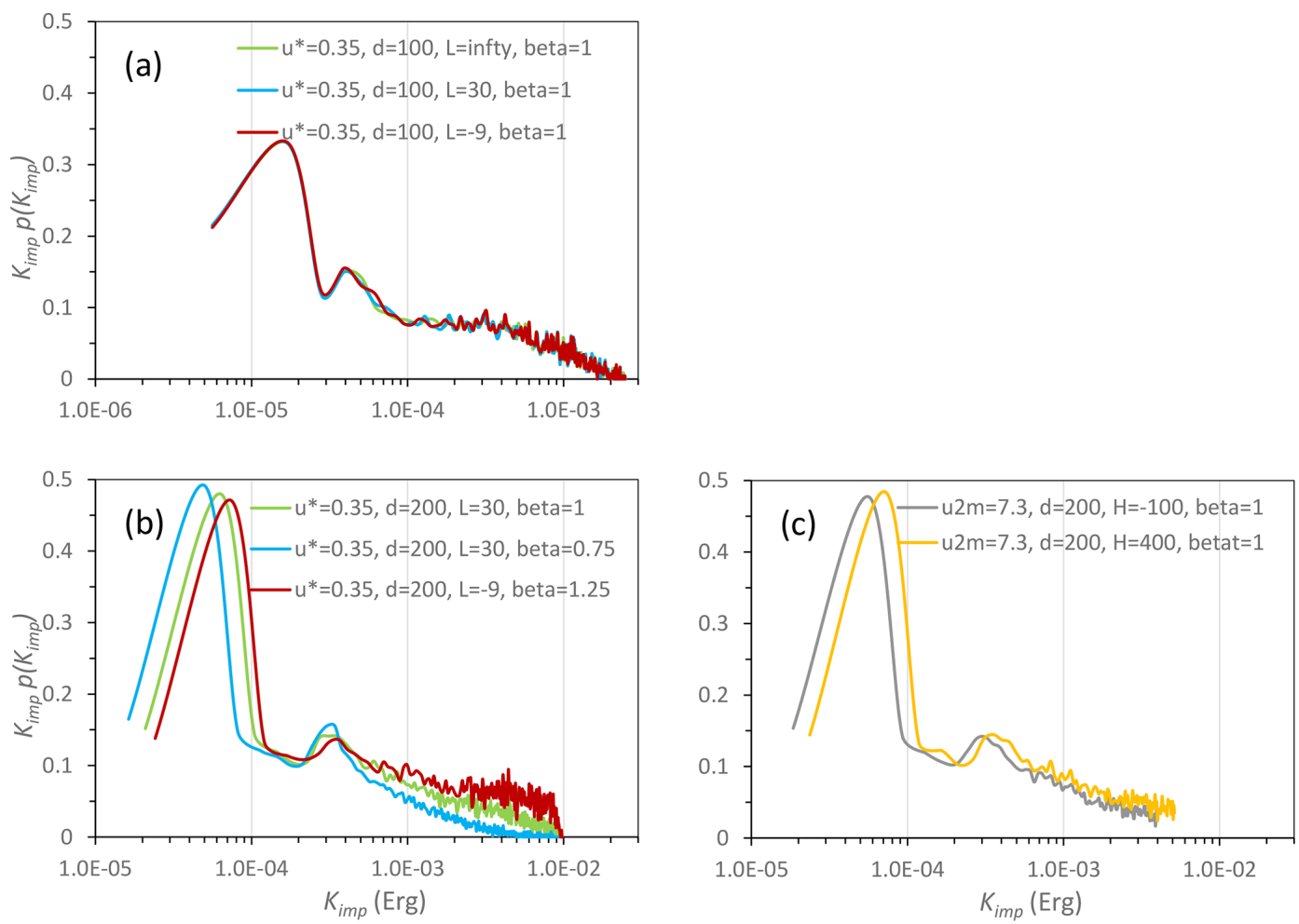

Figure 9. Probability density function $p\left(K_{\mathrm{imp}}\right)$ (plotted in $K_{\mathrm{imp}} p\left(K_{\mathrm{imp}}\right)$ against $K_{\mathrm{imp}}$ in logarithmic scale) for the numerical experiments. In (a), $p\left(K_{\mathrm{imp}}\right)$ is shown for $u_{*}=0.35 \mathrm{~m} \mathrm{~s}^{-1}, d=100 \mu \mathrm{m}$ and $\beta=1$ but for three different Obukhov lengths $L=\infty, 30 \mathrm{~m}$ and $-9 \mathrm{~m}$. In (b), the effect of $\beta$ on $p\left(K_{\mathrm{imp}}\right)$ is examined; in (c), the effect of stability on $p\left(K_{\mathrm{imp}}\right)$ with given mean wind speed at $z=2 \mathrm{~m}$ is examined.
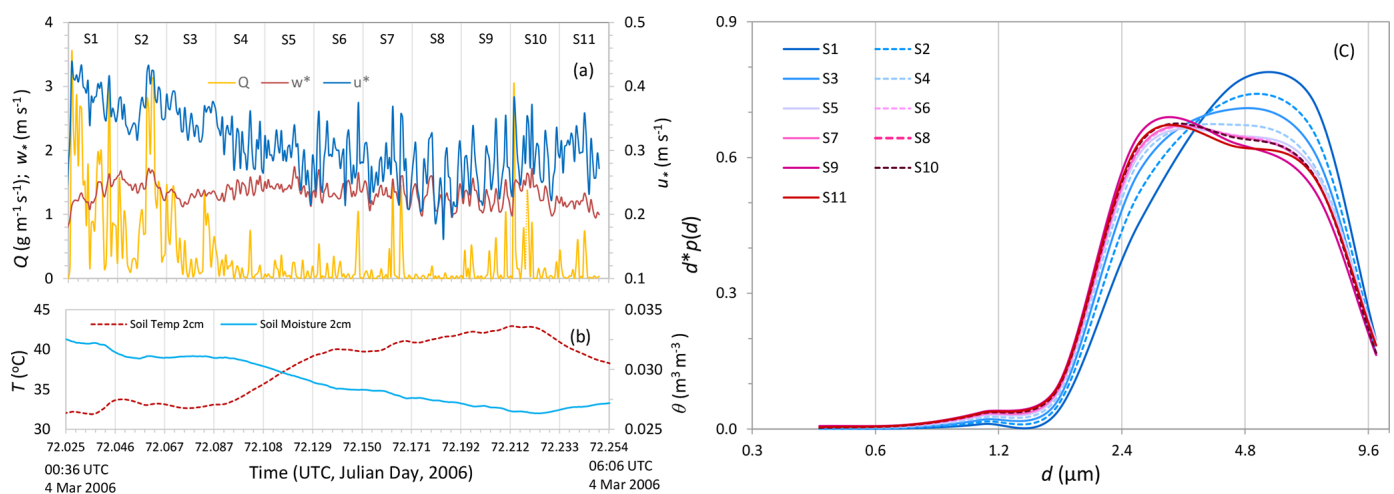

Figure 10. (a) Time series of streamwise saltation flux, $Q\left(\mathrm{~g} \mathrm{~m}^{-1} \mathrm{~s}^{-1}\right)$; convective scaling velocity, $w_{*}\left(\mathrm{~m} \mathrm{~s}^{-1}\right)$; and friction velocity, $u_{*}$ $\left(\mathrm{m} \mathrm{s}^{-1}\right)$, for Event-12. The time span of Event-12 is divided into 11 half-hourly sections, labelled as S1, S2, etc. (b) Same as (a) but for soil temperature, $T\left({ }^{\circ} \mathrm{C}\right)$, and soil moisture, $\theta\left(\mathrm{m}^{3} \mathrm{~m}^{-3}\right)$, both at $0.02 \mathrm{~m}$ depth. (c) Dust PSDs averaged over Sects. S1, S2, etc.

of $2 \mathrm{~cm}$ soil temperature and soil moisture. For the whole event, the $\mathrm{ABL}$ was unstable, with $w_{*}$ fluctuating around $1.64 \pm 0.12 \mathrm{~m} \mathrm{~s}^{-1}$. Initially (e.g. S1 and $\mathrm{S} 2$ ), $u_{*}$ was relatively large, exceeding $0.4 \mathrm{~m} \mathrm{~s}^{-1}$ at times, but then eased to around $0.3 \mathrm{~m} \mathrm{~s}^{-1}$. $Q$ generally followed the variations of $u_{*}$. Yet, the dust PSD showed a systematic shift from coarser to finer particles, as the event progressed. The dust PSD dependency on $u_{*}$ of Event-12 does not conform with the results for Event-11 (Fig. 6) or the overall results (Fig. 4a).
Ishizuka et al. (2008) noticed that prior to Event-12, weak rainfall occurred (R4, Fig. 5b) and, consequently, weak crusts formed on the soil surface. Apparently, the lightly crusted surface prevented the emission of fine dust particles in the early stages of Event-12. As the event progressed, soil temperature increased, soil moisture decreased (Fig. 10b) and the saltation during the early stages caused the destruction of the crusts and the amount of fine dust particles available for emission increased. These are the most likely reasons for 


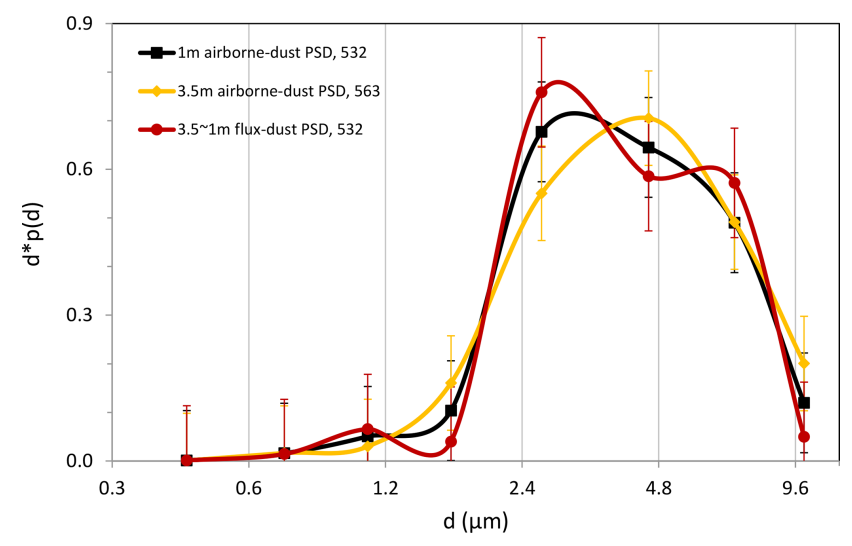

Figure 11. JADE Event-10 averaged airborne-dust PSD measured at $1 \mathrm{~m}$ (532 one-minute samples) and $3.5 \mathrm{~m}$ (563 one-minute samples) using OPCs. Also shown are standard-error bars. For comparison, the Event-10 averaged (over 532 one-minute samples) emission-flux PSD calculated using Eq. (5) is also plotted.

why, in the later stages of Event-12, an increased fraction of fine dust was released, although the atmospheric stability did not significantly change and $u_{*}$ actually decreased.

\subsection{Uncertainties}

Several issues are related to the uncertainties of the analysis. First, the approximation of emission-dust PSD with airbornedust PSD measured at some height above ground causes uncertainties, because airborne-dust PSD is height dependent as a consequence of the dust-transport processes (e.g. diffusion and deposition) in the atmosphere, which are both particlesize and turbulence-property dependent. As our understanding of these processes is not complete and dust measurements have inaccuracies, a careful selection of the data for the analysis is necessary. Figure 11 shows a comparison of Event10 averaged airborne-dust PSDs at 1 and $3.5 \mathrm{~m}$. Ishizuka et al. (2014) suggested to exclude the $2 \mathrm{~m}$ OPC data, because they do not correlate well with the $1 \mathrm{~m}$ and $3.5 \mathrm{~m}$ OPC data. The PSDs derived from the $2 \mathrm{~m}$ OPC data do show unexpected differences in comparison to those from the $1 \mathrm{~m}$ and $3.5 \mathrm{~m}$ OPC data. We thus have excluded the $2 \mathrm{~m}$ OPC data from our analysis. The PSDs derived from the $1 \mathrm{~m}$ and $3.5 \mathrm{~m}$ OPC data somewhat differ, with the peak particle size shifted by about two micrometres, i.e. airborne-dust PSD has a noticeable change with height. This also implies that it would be very difficult to compare airborne-dust PSD measured at different locations and under different conditions without a well-established framework equivalent to the MoninObukhov similarity theory.

Also shown in Fig. 11 is the Event-10 averaged emissionflux PSD calculated using Eq. (5). Dust fluxes for different particle size bins are calculated using the $3.5 \mathrm{~m}$ and $1 \mathrm{~m} \mathrm{OPC}$ data with the gradient method (Gillette et al., 1972) and corrections (Shao et al., 2011). As dust flux is proportional to the negative gradient of dust concentration, emission-flux PSD basically describes how dust-concentration gradient (in our case $\left.-\left(c_{3.5 \mathrm{~m}}-c_{1 \mathrm{~m}}\right)\right)$ depends on particle size.

Although dust PSDs derived from $1 \mathrm{~m} \mathrm{OPC}$ and $3.5 \mathrm{~m}$ OPC data differ, qualitatively they show similar dependencies of dust PSD on $u_{*}$ and $w_{*}$. Figure 12a compares the averaged dust PSDs for two $u_{*}$ categories using the $1 \mathrm{~m} \mathrm{OPC}$ and $3.5 \mathrm{~m}$ OPC data. For both cases, the dust PSD dependency on $u_{*}$ is visible. Figure $12 \mathrm{~b}$ compares the averaged dust PSD for a given $u_{*}$ category $\left(0.35-0.45 \mathrm{~m} \mathrm{~s}^{-1}\right)$ under stable and unstable conditions. Again, both the $1 \mathrm{~m}$ OPC and $3.5 \mathrm{~m}$ OPC dust PSDs show dependency on $w_{*}$.

It needs to be clarified whether using 1 min averages of shear stress, saltation flux and dust flux are appropriate for the study. Related to this question are two intertwined yet somewhat different scaling issues, namely, (1) the scaling of turbulent flux and the corresponding mean variable of boundary-layer turbulent flows (i.e. the flux-gradient relationship); and (2) the scaling of aeolian fluxes and atmospheric forcing (i.e. saltation/dust-emission intermittency). It is usual in boundary-layer meteorology to compute a turbulent flux from the profile of the corresponding mean quantity, e.g. mean shear stress from mean wind profile, and the time interval for the mean is typically 15 to $30 \mathrm{~min}$ such that the assumptions of horizontal homogeneity and stationarity commonly made in boundary-layer studies are met. This issue is not yet fully resolved even in boundary-layer studies. For example, large-eddy models (with spatial resolution of several metres and temporal resolution of seconds) frequently use the Monin-Obukhov similarity functions to estimate subgrid surface stress from the grid-resolved speed. In this study, we distinguish the $1 \mathrm{~min}$ averages of $u_{*}$ from the mean shear stress of the boundary-layer flow to emphasize the importance of shear stress fluctuations. The problem of how to scale aeolian fluxes is not new (e.g. Shao and Mikami, 2005). Dupont (2020) has a dedicated paper on this problem and stated that $u_{*}$ is a suitable scaling parameter for dust flux over usual 15-30 min time intervals, but at smaller time resolution, wind becomes more relevant to scale dust fluxes, which is a conclusion similar to that reached in Sterk et al. (1998). The studies of Stout and Zobeck (1997) and Sterk et al. (1998), as well as more recently Klose and Shao (2012) and Klose et al. (2014), all pointed to the importance of taking instantaneous shear stress into consideration for aeolian dynamics. As Shao (2008) explains, $\tau_{\text {inst }}$ is proportional to $U^{\prime 2}$, where $\tau_{\text {inst }}$ is instantaneous shear stress and $U^{\prime}$ instantaneous wind speed. The argument of Shao (2008) reasonably well explains the conclusions of Sterk et al. (1998) and Dupont (2020). Liu et al. (2018, Fig. 7) analysed co-spectrum of saltation flux and shear stress and showed that they have a correlation peak at $2 \times 10^{-3} \mathrm{~Hz}$, corresponding to gusts or large eddies of around $10 \mathrm{~min}$ in turbulent flows. These considerations suggest that to average shear stress and aeolian fluxes over $1 \mathrm{~min}$ is appropriate and has the advantage of showing how dust emission 

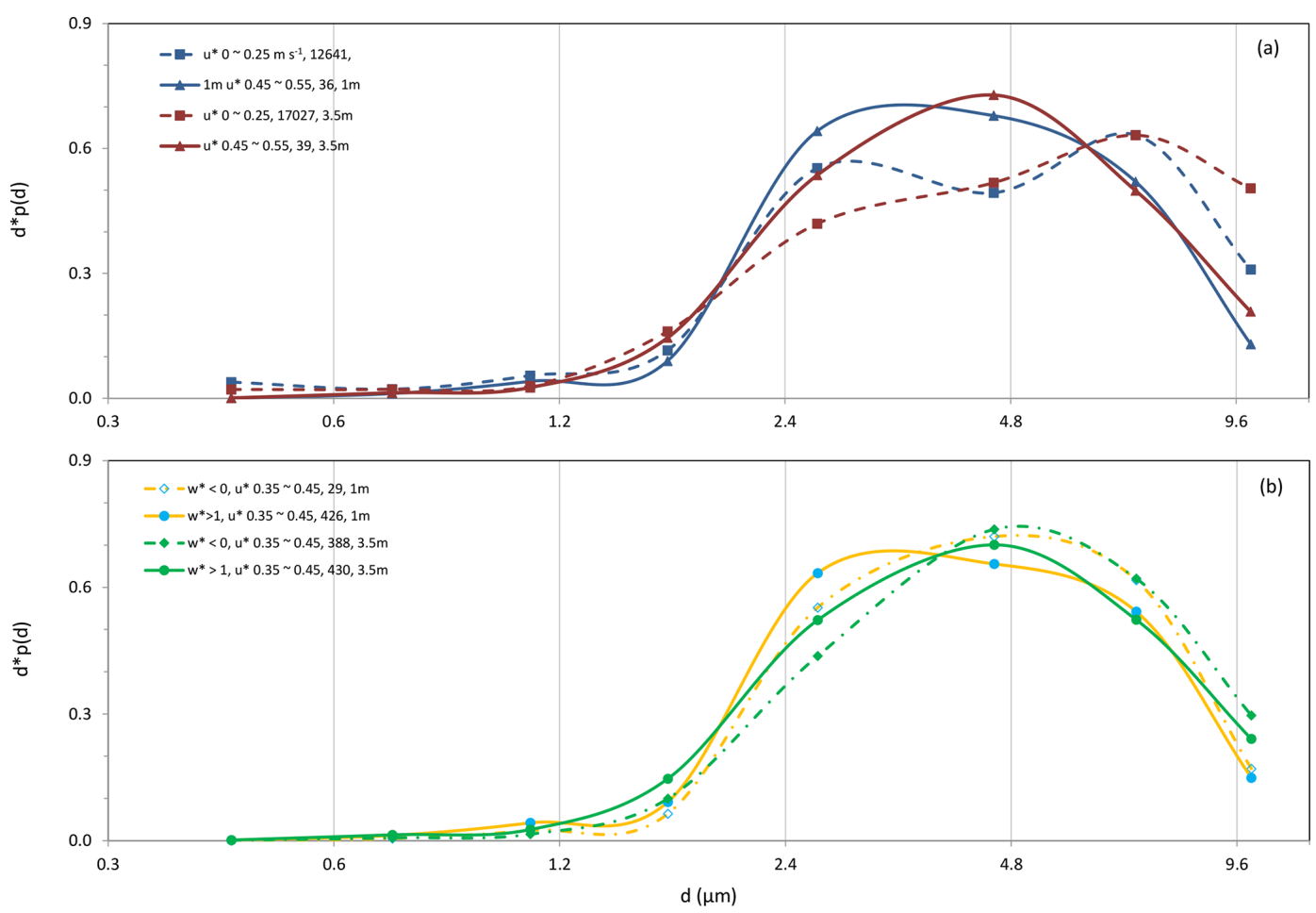

Figure 12. (a) JADE averaged airborne-dust PSD measured at 1 and $3.5 \mathrm{~m}$ for two $u_{*}$ categories. (b) Same as (a) but for one $u_{*}$ category and two different stabilities.

is related to turbulence. We have emphasized throughout this paper that turbulence is key to understanding the dependency of dust PSD on ABL stability, because the most essential difference among ABLs of different stability are the intensity and structure of turbulence.

As far as averaged dust PSDs are concerned, we have compared the dust PSDs averaged for different $u_{*}$ categories using $1 \mathrm{~min}$ averaged data and $10 \mathrm{~min}$ averaged data. The results are almost the same.

\section{Conclusions}

Using JADE data, we showed that dust PSD is dependent on friction velocity $u_{*}$. This finding is consistent with the wind-tunnel study of Alfaro et al. (1997). The JADE data support the claim that dust PSD is saltation-bombardment dependent and does not support the hypothesis that dust PSD is invariant.

The JADE data show that dust PSD, as well as saltation PSD, also depends on ABL stability. This finding is consistent with the results of Khalfallah et al. (2020). Dust PSD is dependent on ABL stability for two reasons. First, $u_{*}$ is a stochastic variable and the PDF of $u_{*}$ profoundly influences the magnitude of saltation flux, $Q$, because of the non-linear relationship between $Q$ and $u_{*}$. With fixed $u_{*}$ mean, a larger $u_{*}$ variance corresponds to a larger $Q$. Unstable ABL has in general larger $u_{*}$ variances which generate stronger salta- tion bombardment and produce the emission of finer dust particles. Second, in unstable ABL turbulence is generally stronger, and in strong turbulent flows the proportion of saltation particles with large impacting kinetic energy is larger than in weak turbulent flows. Consequently, saltation in unstable ABLs is more fully developed and saltation bombardment has higher intensity.

The dependencies of dust PSD on $u_{*}$ and ABL stability are ultimately attributed to the statistic behaviour of $u_{*}$, i.e. its PDF $p\left(u_{*}\right)$ or more simply its mean and variance. These dependencies point to the same fact that, for a given soil, saltation bombardment plays a determining role for the dust PSD. Stronger saltation causes in general the emission of finer dust.

The dependency of dust PSD on $u_{*}$ and ABL stability is made complicated by soil surface condition. In the case of strong saltation and very weak surface and particle binding, the dust PSD dependency on $u_{*}$ may become less obvious. In the case of strong surface and particle binding, dust emission in certain size ranges may be prohibited.

Data availability. Data can be accessed by contacting the corresponding authors.

Supplement. The supplement related to this article is available online at: https://doi.org/10.5194/acp-20-12939-2020-supplement. 
Author contributions. YS performed the data analyses and drafted the article. JZ and NH contributed to the conception of the study, the data analysis and the writing of the article. MI, MM and JL conceived, designed and performed the experiments and helped finalize the paper.

Competing interests. The authors declare that they have no conflict of interest.

Acknowledgements. We thank the projects that financially support this work. We are grateful to the editor, the three referees, Sylvain Dupont and Jasper Kok, for their constructive comments and helpful discussions.

Financial support. This research has been supported by the National Key Research and Development Program of China (grant no. 2016YFC0500901), the National Natural Foundation of China (grant nos. 11602100 and 11172118), the Fundamental Research Funds for the Central Universities (grant no. lzujbky-2020-cd06), and the Grants-in-Aid for Scientific Researches (A) from the Japan Society for the Promotion of Science (grant nos. 17201008 and 20244078).

Review statement. This paper was edited by Hang $\mathrm{Su}$ and reviewed by three anonymous referees.

\section{References}

Albani, S., Mahowald, N. M., Perry, A. T., Scanza, R. A., Zender, C. S., Heavens, N. G., Maggi, V., Kok, J. F., and OttoBliesner, B. L.: Improved dust representation in the Community Atmosphere Model. J. Adv. Model. Earth Sy., 6, 541-570, https://doi.org/10.1002/2013MS000279, 2014

Alfaro, S. C., Gaudichet, A., Gomes, L., and Maille, M.: Modeling the size distribution of a soil aerosol produced by sandblasting. J. Geophys. Res.-Atmos., 102, 11239-11249, https://doi.org/10.1029/97JD00403, 1997.

Astrom, J. A.: Statistical models of brittle fragmentation. Adv. Phys., 55, 247-278, https://doi.org/10.1080 /00018730600731907, 2006.

Businger, J. A., Wyngaard, J. C., Izumi, J., and Bradley, E. F.: Flux-Profile Relationships in the Atmospheric Surface Layer, J. Atmos. Sci., 28, 181-189, https://doi.org/10.1175/15200469(1971)028<0181:FPRITA>2.0.CO;2, 1971.

Csanady, G. T.: Turbulent Diffusion of Heavy Particles in the Atmosphere, J. Atmos. Sci., 20, 201-208, https://doi.org/10.1175/15200469(1963)020<0201:TDOHPI>2.0.CO;2, 1963.

Dupont, S., Scaling of dust flux with friction velocity: time resolution effects, J. Geophys. Res.-Atmos., 125, e2019JD031192, https://doi.org/10.1029/2019JD031192, 2020.
Durána, O., Andreotti, B., and Claudin, P.: Numerical simulation of turbulent sediment transport, from bed load to saltation, Physics of Fluids, 24, 709-737, https://doi.org/10.1063/1.4757662, 2012.

Gillette, D. A., Blifford, I. H., and Fenster, C. R.: Measurements of aerosol size distributions and vertical fluxes of aerosols on land subject to wind erosion. J. Appl. Meteor., 11, 977-987, https://doi.org/10.1175/15200450(1972)011<0977:MOASDA>2.0.CO;2, 1972.

Gillette, D. A., Blifford, I. H., and Fryrear, D. W.: Influence of wind velocity on size distributions of aerosols generated by wind erosion of soils. J. Geophys. Res., 79, 4068-4075, https://doi.org/10.1029/JC079i027p04068, 1974.

Gillette, D. A.: Production of dust that may be carried great distances, Geol. Soc. Am., 186, 11-26, https://doi.org/10.1130/SPE186-p11, 1981.

Giorgi, F., Coppola, E., Solmon, F., Mariotti, L., Sylla, M. B., Bi, X., Elguindi, N., Diro, G. T., Nair, V., Giuliani, G., Turuncoglu, U. U., Cozzini, S., Güttler, I., O’Brien, T. A., Tawfik, A. B., Shalaby, A., Zakey, A. S., Steiner, A. L., Stordal, F., Sloan, L. C., and Brankovic, C.: RegCM4: model description and preliminary tests over multiple CORDEX domains, Clim. Res., 52, 7-29, https://doi.org/10.3354/cr01018, 2012.

Ishizuka, M., Mikami, M., Leys, J. F., Yamada, Y., Heidenreich, S., Shao, Y., and McTainsh, G. H.: Effects of soil moisture and dried raindroplet crust on saltation and dust emission. J. Geophys. Res.-Atmos., 113, D24212, https://doi.org/10.1029/2008JD009955, 2008.

Ishizuka, M., Mikami, M., Leys, J., Yamada, Y., Heidenreich, S., Shao, Y., and McTainsh, G. H.: Effects of soil moisture and dried raindroplet crust on saltation and dust emission, J. Geophys. Res.-Atmos., 113, D24212, https://doi.org/10.1029/2008JD009955, 2008.

Ishizuka, M., Mikami, M., Leys, J. F., Shao, Y., Yamada, Y., and Heidenreich, S.: Power law relation between size-resolved vertical dust flux and friction velocity measured in a fallow wheat field, Aeolian Res., 12, 87-99, https://doi.org/10.1016/j.aeolia.2013.11.002, 2014.

Kaimal, J. C. and Finnigan J. J.: Atmospheric Boundary Layer Flows: Their Structure and Measurements, Bound.-Lay. Meteorol., 72, 213-214, https://doi.org/10.1007/BF00712396, 1995.

Khalfallah, B., Bouet, C., Labiadh, M., Alfaro, S., Bergametti, G., Marticorena, B., Lafon, S., Chevaillier, S., Féron, A., Hease, P., Henry-des-Tureaux, T., Sekrafi, S., Zapf, P., and Rajot, J. L.: Influence of atmospheric stability on the size-distribution of the vertical dust flux measured in eroding conditions over a flat bare sandy field, J. Geophys. Res.-Atmos., 125, e2019JD031185, https://doi.org/10.1029/2019JD031185, 2020.

Klose, M. and Shao, Y.: Stochastic parameterization of dust emission and application to convective atmospheric conditions, Atmos. Chem. Phys., 12, 7309-7320, https://doi.org/10.5194/acp12-7309-2012, 2012.

Klose, M., Shao, Y., Li, X., Zhang, H., Ishizuka, M., Mikami, M., and Leys, J. F.: Further development of a parameterization for convective turbulent dust emission and evaluation based on field observations, J. Geophys. Res.-Atmos., 119, 10441-10457, https://doi.org/10.1002/2014JD021688, 2014.

Kok, J. F.: Does the size distribution of mineral dust aerosols depend on the wind speed at emission?, Atmos. Chem. Phys., 11, 1014910156, https://doi.org/10.5194/acp-11-10149-2011, 2011a. 
Kok, J. F.: A scaling theory for the size distribution of emitted dust aerosols suggests climate models underestimate the size of the global dust cycle, P. Natl. Acad. Sci. USA, 108, 1016-1021, https://doi.org/10.1073/pnas.1014798108, 2011 b.

Kok, J. F., Parteli, E. J., Michaels, T. I., and Karam, D. B.: The physics of wind-blown sand and dust, Reports on Progress, Physics Physical Society, 75, 106901, https://doi.org/10.1088/0034-4885/75/10/106901, 2012.

Laurent, B., Marticorena, B., Bergametti, G., and Mei, F.: Modeling mineral dust emissions from Chinese and Mongolian deserts, Glob. Planet Change, 52, 121-141, https://doi.org/10.1016/j.gloplacha.2006.02.012, 2006.

Li, G., Zhang, J., Herrmann, H. J., Shao, Y., and Huang, N.: Study of aerodynamic grain entrainment in aeolian transport. Geophys. Res. Lett., 47, e2019GL086574, https://doi.org/10.1029/2019GL086574, 2020.

Liu, D., Ishizuka, M., Mikami, M., and Shao, Y.: Turbulent characteristics of saltation and uncertainty of saltation model parameters, Atmos. Chem. Phys., 18, 7595-7606, https://doi.org/10.5194/acp-18-7595-2018, 2018.

Lu, H. and Shao, Y.: A new model for dust emission by saltation bombardment. J. Geophys. Res.-Atmos., 104, 16827-16842, https://doi.org/10.1029/1999JD900169, 1999.

Marticorena, B., Bergametti, G., Aumont, B., Callot, Y., N'Doume, C., and Legrand, M.: Modeling the atmospheric dust cycle: 2. Simulation of Saharan dust sources, J. Geophys. Res., 102, 43874404, https://doi.org/10.1029/96JD02964,1997.

Martin, R. L. and Kok, J. F.: Wind-invariant saltation heights imply linear scaling of aeolian saltation flux with shear stress, Sci. Adv., 3, e1602569, https://doi.org/10.1126/sciadv.1602569, 2017.

Mikami, M., Yamada, Y., Ishizuka, M., Ishimaru, T., Gao, W., and Zeng, F.: Measurement of saltation process over gobi and sand dunes in the Taklimakan desert, China, with newly developed sand particle counter, J. Geophys. Res.-Atmos., 110, D18S02, https://doi.org/10.1029/2004JD004688, 2005.

Owen, R. P.: Saltation of uniform grains in air, J. Fluid. Mech., 20, 225-242, https://doi.org/10.1017/S0022112064001173, 1964.

Pisso, I., Sollum, E., Grythe, H., Kristiansen, N. I., Cassiani, M., Eckhardt, S., Arnold, D., Morton, D., Thompson, R. L., Groot Zwaaftink, C. D., Evangeliou, N., Sodemann, H., Haimberger, L., Henne, S., Brunner, D., Burkhart, J. F., Fouilloux, A., Brioude, J., Philipp, A., Seibert, P., and Stohl, A.: The Lagrangian particle dispersion model FLEXPART version 10.4, Geosci. Model Dev., 12, 4955-4997, https://doi.org/10.5194/gmd-12-4955-2019, 2019.

Raupach, M. R.: Drag and drag partition on rough surfaces, Bound.-Lay. Meteorol., 60, 375-395, https://doi.org/10.1007/BF00155203, 1992.

Reid, J. S., Reid, E. A., Walker, A., Piketh, S., Cliff, S., Al Mandoos, A., Tsay, S.-C., and Eck, T. F.: Dynamics of southwest Asian dust particle size characteristics with implications for global dust research, J. Geophys. Res.-Atmos., 113, D14212, https://doi.org/10.1029/2007JD009752, 2008.
Rice, M. A., Willetts, B. B., and McEwan, I. K., An experimental study of multiple grain-size ejecta produced by collisions of saltating grains with a flat bed, Sedimentology, 42, 695-706, https://doi.org/10.1111/j.1365-3091.1995.tb00401.x, 1995.

Rice, M. A., Willetts, B. B., and McEwan, I. K., Observations of collisions of saltating grains with a granular bed from high-speed cine-film, Sedimentology, 43, 21-31, https://doi.org/10.1111/j.1365-3091.1996.tb01456.x, 1996.

Rosenberg, P. D., Parker, D. J., Ryder, C. L., Marsham, J. H., Garcia-Carreras, L., Dorsey, J. R., Briiks, I. M., Dean A. R., Crosier, J., McQuaid, J. B., and Washington, R.: Quantifying particle size and turbulent scale dependence of dust flux in the Sahara using aircraft measurements, J. Geophys. Res.-Atmos., 119, 7577-7598, https://doi.org/10.1002/2013JD021255, 2014.

Shao, Y.: A model for mineral dust emission. J. Geophys. Res.-Atmos., 106, 20239-20254, https://doi.org/10.1029/ 2001JD900171, 2001.

Shao, Y.: Simplification of a dust emission scheme and comparison with data, J. Geophys. Res., 109, https://doi.org/10.1029/2003JD004372, 2004.

Shao, Y.: Physics and Modelling of Wind Erosion, Springer, Chapter 6 and Chapter 8, https://doi.org/10.1007/978-1-4020-8895-7, 2008.

Shao, Y., Ishizuka, M., Mikami, M., and Leys, J. F.: Parameterization of size-resolved dust emission and validation with measurements, J. Geophys. Res.-Atmos., 116, D08203, https://doi.org/10.1029/2010JD014527, 2011.

Shao, Y. and Mikami, M.: Heterogeneous Saltation: Theory, Observation and Comparison, Bound.-Lay. Meteorol., 115, 359-379, https://doi.org/10.1007/s10546-004-7089-2, 2005.

Shao, Y., Raupach, M. R., and Findlater, P. A.: Effect of saltation bombardment on the entrainment of dust by wind, J. Geophys. Res.-Atmos., 98, 12719-12726, https://doi.org/10.1029/93JD00396, 1993.

Sow, M., Alfaro, S. C., Rajot, J. L., and Marticorena, B.: Size resolved dust emission fluxes measured in Niger during 3 dust storms of the AMMA experiment, Atmos. Chem. Phys., 9, 38813891, https://doi.org/10.5194/acp-9-3881-2009, 2009.

Sterk, G., Jacobs, A. F. G., and van Boxel, J. H.: The effect of turbulent flow structures on saltation sand transport in the atmospheric boundary layer, Earth Surf. Proc. Land., 23, 877-887, https://doi.org/10.1002/(SICI)10969837(199810)23:10<877::AID-ESP905>3.0.CO;2-, 1998.

Stout, J. E. and Zobeck, T. M.: Intermittent saltation. Sedimentology, 44, 959-970, https://doi.org/10.1046/j.13653091.1997.d01-55.x, 1997.

Stull, R. B.: An Introduction to Boundary Layer Meteorology, Kluwer Academic Publishers, Boston, https://doi.org/10.1007/978-94-009-3027-8, 1988.

Ungar, J. E. and Haff, P. K.: Steady state saltation in air, Sedimentology, 34, 289-299, https://doi.org/10.1111/j.13653091.1987.tb00778.x, 1987.

Walklate, P. J.: A random-walk model for dispersion of heavy particles in turbulent air flow, Bound.-Lay. Meteorol., 39, 175-190, https://doi.org/10.1007/BF00121873, 1987. 
Wang, L. and Stock, D. E.: Dispersion of Heavy Particles by Turbulent Motion, J. Atmos. Sci., 50, 1897-1913, https://doi.org/10.1175/15200469(1993)050<1897:DOHPBT>2.0.CO;2, 1993.

Webb, N. P., Chappell, A., LeGrand, S. L., Ziegler, N. P., and Edwards, B. L.: A note on the use of drag partition in aeolian transport models, Aeolian Res., 42, https://doi.org/10.1016/j.aeolia.2019.100560, 2019.
Yahaya, S., Frangi, J. P., and Richard, D. C.: Turbulent characteristics of a semiarid atmospheric surface layer from cup anemometers - effects of soil tillage treatment (Northern Spain), Ann. Geophys., 21, 2119-2131, https://doi.org/10.5194/angeo21-2119-2003, 2003.

Zender, C. S., Bian, H., and Newman, D.: Mineral Dust Entrainment and Deposition (DEAD) model: Description and 1990s dust climatology, J. Geophys. Res., 108, 4416, https://doi.org/10.1029/2002JD002775, 2003. 